\title{
High tolerance of symbiotic larvae of Pocillopora damicornis to thermal stress
}

\author{
Dwi Haryanti ${ }^{1 *}$, Naoko Yasuda', Saki Harii ${ }^{2}$ and Michio Hidaka ${ }^{1}$
}

\begin{abstract}
Background: When coral planulae, which use a horizontal mode of symbiont transmission, are inoculated with Symbiodinium, they suffer greater oxidative stress under strong light or high-temperature stress than non-symbiotic counterparts. Thus, dinoflagellate symbionts may become a source of reactive oxygen species (ROS) under stress. However, it remains unknown whether vertically transmitted symbionts negatively affect coral larvae under stress. We investigated the thermal tolerance of symbiotic planulae of a vertical transmitter coral, Pocillopora damicornis.

Results: $P$. damicornis larvae, which have a large number of symbionts, survived the high-temperature treatment $\left(32^{\circ} \mathrm{C}\right.$ ) for 2 weeks. Significant reductions in Symbiodinium cell density were observed, but these did not lead to increased mortality of planulae during the 2-week experimental period. Although no significant difference was detected in the percentage of apoptotic cells between temperature treatment groups, pre-bleaching larvae exposed to $31{ }^{\circ} \mathrm{C}$ tended to exhibit higher percentages of apoptotic (TUNEL-positive) cells in the gastrodermis than $32^{\circ} \mathrm{C}$-treated larvae, which contained reduced numbers of Symbiodinium cells.

Conclusions: Symbiotic larvae of $P$. damicornis survived well under high-temperature conditions, although their Symbiodinium cell density decreased. This suggests that $P$. damicornis larvae have the capacity to reduce the symbiont cell density without a harmful effect on their survivorship under thermal stress. Further studies on antioxidant systems and possible suppression of apoptotic pathways are necessary to elucidate the mechanism underlying the high thermal tolerance of symbiotic larvae of $P$. damicornis.
\end{abstract}

Keywords: Apoptosis; Bleaching; Coral; Larvae; Survivorship; Symbiosis

\section{Background}

Approximately $80 \%$ of scleractinian coral species are broadcast spawners and release gametes, while more than $10 \%$ coral species are brooders and release larvae that have developed within their polyps (Baird et al. 2009a; Harrison 2011). Reef-building scleractinian corals associate with symbiotic dinoflagellates called Symbiodinium spp. Approximately $80 \%$ of spawning corals release Symbiodinium-free eggs, and less than $20 \%$ of brooding species release Symbiodinium-free larvae (Baird et al. 2009a). The offspring of these corals must acquire symbiotic algae from the environment (horizontal transmission of symbionts) in each generation. On the other hand, more than $80 \%$ of brooders release Symbiodinium-containing larvae (Baird et al. 2009a), and

\footnotetext{
* Correspondence: dwiharyanti@gmail.com

'Department of Chemistry, Biology and Marine Science, University of the Ryukyus, Nishihara, Okinawa 903-0213, Japan

Full list of author information is available at the end of the article
}

some spawners such as Porites, Montipora, and some Pocillopora species release Symbiodinium-containing eggs. The offspring of these corals inherit symbiotic algae from their maternal colony (vertical transmission; Harrison and Wallace 1990).

Coral larvae containing Symbiodinium might obtain energy from algal photosynthesis (e.g., Harii et al. 2002). It is suggested that not all larval energy requirements are met by the lipids provisioned within the egg, but that some are sourced from the photosynthetic products of symbiotic algae. Under favorable circumstances, the presence of symbiotic algae within larvae has the potential to extend the larval lifespan (Cantin et al. 2009; Harii et al. 2010). However, under stressful conditions, such as high temperatures or excessive light irradiance, symbiotic dinoflagellates might become a source of reactive oxygen species (ROS), which lead to disruption of the symbiosis, or bleaching (Weis 2008). Thus, coral planulae that contain Symbiodinium might be more sensitive

\section{实}


to environmental stress than Symbiodinium-free planulae. Since the larvae of Acropora corals acquire symbionts via horizontal transmission, it is possible to investigate the effect of inoculation of Symbiodinium cells on the stress sensitivity of the larvae. Yakovleva et al. (2009) showed that larvae of Acropora intermedia inoculated with Symbiodinium exhibited lower survivorship, higher superoxide dismutase (SOD) activity, and higher contents of malondialdehyde, an indicator of lipid peroxidation, under thermal stress than did Symbiodinium-free larvae. It was also reported that if non-symbiotic Acropora tenuis larvae are inoculated with Symbiodinium, the symbiotic larvae suffer greater DNA damage than Symbiodiniumfree larvae when exposed to natural sunlight for 3 days (Nesa et al. 2012). These studies suggest that symbiotic larvae suffer more severe oxidative stress compared to non-symbiotic larvae because algal symbionts generate reactive oxygen species (ROS) under stress conditions. Another study using aggregates of dissociated coral cells (tissue-balls) showed that under thermal stress, tissue balls with higher Symbiodinium density suffered more severe DNA damage and died more rapidly than those with low Symbiodinium density (Nesa and Hidaka 2008; Nesa and Hidaka 2009). This again supports the notion that algal symbionts become a burden for host corals under stressful conditions.

Different Symbiodinium types have different physiologies, including different tolerances to heat (Glynn et al. 2001; Baker et al. 2004; van Oppen et al. 2005) and light (Abrego et al. 2008). The physiology of the symbiont helps determine that of the host. For example, the heattolerant Symbiodinium D increases the tolerance of $A$. millepora colonies by $1-1.5{ }^{\circ} \mathrm{C}$ compared to those with Symbiodinium C1 (Berkelmans and van Oppen 2006). Similarly, Pocillopora damicornis colonies hosting clade D Symbiodinium show higher survival rate than those harboring clade $\mathrm{C}$ at elevated temperatures without growth disadvantage (Cunning et al. 2015). However, the host also controls some thermal tolerance patterns (Baird et al. 2009b), because A. tenuis juveniles associating with clade $\mathrm{C} 1$ are more stress-tolerant than those associated with clade D (Abrego et al. 2008).

It is not known how the presence of algal symbionts affects larval survivorship under stress in vertical transmitters and whether they are more sensitive to environmental stress than the Symbiodinium-free larvae of horizontal transmitter species. It is also possible that, if algal symbionts become a burden for the larvae during the planktonic stage, the larvae of vertical transmitter corals might have highly efficient defense systems against oxidative stress.

In the present study, we investigated the survivorship of symbiotic larvae of Pocillopora damicornis, a vertical transmitter, under thermal stress. We also studied changes in symbiont density and the occurrence and distribution pattern of apoptotic host cells in P. damicornis larvae to determine if temperature stress causes decreased symbiont densities and increased mortality of host cells as observed in adult corals. Symbiodinium types in some maternal colonies were also identified.

\section{Methods}

\section{Collection and maintenance of larvae}

Nine and five colonies of $P$. damicornis (ca. $10 \mathrm{~cm}$ in diameter) were collected from the reef at Sesoko Island $\left(26^{\circ} 38^{\prime} 53.6^{\prime \prime} \mathrm{N}, 127^{\circ} 51^{\prime} 13.2^{\prime \prime}\right.$ E) in July 2010 and June 2011, respectively. In June 2012, nine colonies were collected from Bise, $6.7 \mathrm{~km}$ north of Sesoko Island. All colonies were collected at depths of less than $1 \mathrm{~m}$ during low tide. The sea surface temperature at Sesoko Island ranged from 26.5 to $30.6{ }^{\circ} \mathrm{C}$ during the collection months (Record of coastal observation at the Sesoko Station, Tropical Biosphere Research Center, University of the Ryukyus). After sampling, colonies were transferred to an outdoor tank supplied with non-filtered seawater at Sesoko Station. Planulae released during the first quarter moon of August 2010, July 2011, and June 2012 were collected using planula collectors (Hidaka et al. 1997). Released planulae were removed from the collectors and transferred into 0.5 - $\mathrm{L}$ plastic chambers filled with filtered seawater $(0.2 \mu \mathrm{m})$. Each chamber contained planulae derived from one source colony. The seawater in the chambers was changed daily until the planulae were used for the experiment.

\section{Stress experiment}

Planulae derived from three maternal colonies were used in the 2010 and 2011 experiments, while planulae derived from four maternal colonies were used in the 2012 experiment. Thirty planulae derived from the same maternal $P$. damicornis colony were placed in a glass bottle filled with $100 \mathrm{ml}$ of filtered seawater, and three such bottles, each containing planulae derived from different maternal colonies, were prepared for each temperature treatment in the 2010 and 2011 experiments. In 2012, four bottles, each containing 20 planulae derived from the same maternal colony, were prepared for each temperature treatment.

The planulae were exposed to temperatures of $27{ }^{\circ} \mathrm{C}$ (control), $30{ }^{\circ} \mathrm{C}$ or $31{ }^{\circ} \mathrm{C}$ (medium), and $32{ }^{\circ} \mathrm{C}$ (high) using water baths (E-thermobucket waterbath, TAITEC) under 12:12-h light-dark cycle of moderate light intensity $\left(100 \mu \mathrm{mol} \mathrm{m} \mathrm{m}^{-2}\right)$. This temperature range encompasses current and future project temperature conditions at Sesoko Island, Okinawa, in summer, as the global temperature is predicted to rise at least $2{ }^{\circ} \mathrm{C}$ by the end of this century (Hoegh-Guldberg et al. 2007). Halogen lamps were used as the light source, and light intensity was 
measured using a LI-COR light meter (Model LI-250, USA). The stress exposure experiments were conducted for approximately 2 weeks. Seawater in the bottles was changed daily, and the number of live planulae was counted daily for 13-15 days in all experiments.

To enumerate Symbiodinium cells per planula, three to four $P$. damicornis planulae were sampled before and after the stress exposure experiments. A planula was homogenized in a $1.5-\mathrm{ml}$ tube with $100-\mu \mathrm{l}$ of seawater. An aliquot of the homogenate was used to count the number of Symbiodinium cells under a light microscope using a hemocytometer.

\section{Symbiodinium genotypes in maternal colonies}

DNA was extracted from ethanol-preserved samples of adult fragments from three colonies of $P$. damicornis used as source of planulae in the 2011 experiment following the guanidine extraction protocol (Sinniger et al. 2010). We extracted DNA from the adult colony assuming that the parental colony of P. damicornis gives a similar type of symbiont to the larvae as described in Montipora capitata (Padilla-Gamiño et al. 2012). The internal transcribed spacer 2 (ITS2) region of the rDNA was amplified for each DNA extraction and analyzed by denaturing gradient gel electrophoresis (DGGE). The primer pair ITSintfor and ITS2clamp was used to amplify the ITS2 region under conditions specified by LaJeunesse et al. (2003). Amplified ITS2 fragments were separated on a DGGE DCode system (BIO-RAD) at $90 \mathrm{~V}$ for $15 \mathrm{~h}$ using $8 \%$ polyacrylamide gels (37.5:1 acrylamide/bis) with an internal gradient of $25-70 \%$ denaturants (formamide and urea). The gels were stained with SYBR Green (Sigma), and the bright bands were cut, eluted in $10 \mu \mathrm{l} \mathrm{H}_{2} \mathrm{O}$, re-amplified using the ITSintfor and ITS2reverse primers, and sequenced by Macrogen Japan Co. Ltd. Sequences were identified by a local BLAST search using the GeoSymbio database (Franklin et al. 2012).

\section{Detection of apoptotic cells in Pocillopora damicornis larvae exposed to thermal stress}

After a 14-day stress treatment in 2010, three larvae from each container were fixed in $10 \%$ neutral buffered formalin and stored at $4{ }^{\circ} \mathrm{C}$ until processing. They were then dehydrated in a graded series of ethanol and embedded in Paraplast plus (Sigma P3683). Longitudinal sections $5-\mu \mathrm{m}$ thick were cut, and two consecutive sections were randomly selected from three regions within the specimen. One from each of the consecutive sections was subjected to hematoxylin and eosin staining, and the remaining sections were processed for terminal deoxynucleotidyl transferase dUTP-biotin nick end labeling (TUNEL) assay, which is widely used to detect 3 '-ends of DNA fragments in paraffin-embedded tissue sections. The TUNEL assay was performed following the manual provided with the kit (Chemicon S7111) with a slight modification (50\% reduction) of the concentrations of the chemical reagents. The sections were observed under a fluorescence microscope (Nikon Optiphot-2) using a blue excitation filter (wave length; $495 \mathrm{~nm}$ ) for anti-digoxigenin-fluorescein-labeled (TUNEL-positive) nuclei or an ultraviolet filter (wave length; $365 \mathrm{~nm}$ ) for nuclei counterstained with DAPI. Photomicrographs of the same areas were taken under blue light and then UV excitation using a digital camera (Nikon Digital Sight DS-L1).

The labeling index (LI) for TUNEL-positive cells, which indicates the proportion of cells undergoing apoptosis, was calculated by dividing the number of fluorescein-labeled nuclei by the total number of nuclei stained with DAPI. At least three photographs were taken for each of three sections from each specimen. In total, 18 photographs (each photographed area $5.3 \times 10^{4}$ $\mu \mathrm{m}^{2}$ ) were used for each stress treatment. If symbiotic algae become a source of ROS under stress (Weis 2008; Saragosti et al. 2010; McGinty et al. 2012), we expect apoptosis in the neighboring host cells, that is, the gastrodermal cells. Apoptosis of gastrodermal cells was initially observed before the onset of bleaching (Ainsworth et al. 2008). The average LI was calculated for the epidermis and the gastrodermis separately for each specimen. The number of replicates was three for each treatment, as three planulae derived from different colonies were used for LI measurements. Positive control slides were treated with DNase after the process of antigen retrieval (image not shown). No TUNEL-positive signals were detected in the negative control slides that had been incubated with deionized water instead of TdT enzyme (image not shown).

\section{Statistical analyses}

Kaplan-Meier tests were used to analyze the survivorships of $P$. damicornis planulae. Significant differences in the numbers of Symbiodinium cells per planula were tested among the temperature treatments using a oneway ANOVA followed by Tukey's HSD test. Square root transformation was performed to analyze the 2012 Symbiodinium density data so that the data meet the parametric requirements (Shapiro-Wilk test for normality and Levene test for homoscedasticity). When the number of replicates was fewer than three, the data were excluded from the statistical analyses. All tests were performed using STATISTICA (ver. 6.0). Significant differences in the labeling index of TUNEL-positive cells were tested among treatment groups using a one-way ANOVA and between the gastrodermis and epidermis using Welch's $t$-test (R ver. 2.15.1). 


\section{Results}

Survivorship, Symbiodinium density of Pocillopora damicornis larvae

Most $P$. damicornis planulae survived the high-temperature treatment $\left(32{ }^{\circ} \mathrm{C}\right)$ for 2 weeks in all of the experiments (Fig. 1). There was no significant difference in the survivorship of $P$. damicornis larvae among different temperaturetreated groups (Kaplan-Meier test, $\mathrm{df}=3, p=0.99$ in 2010, $p=0.40$ in 2011, and $p=0.59$ in 2012).

Planulae of $P$. damicornis contained many Symbiodinium cells that were vertically transmitted from the maternal colony. The average numbers $( \pm \mathrm{SE})$ of symbionts at the commencement of the stress exposure experiments were $1.70 \sim 2.78 \times 10^{4}$ cells planula $^{-1}$ in the 3 years of experiments. After two weeks of exposure, the Symbiodinium cell densities were significantly lower at $32{ }^{\circ} \mathrm{C}$ compared to the control temperature $\left(27^{\circ} \mathrm{C}\right)$ group (Fig. 2) (Tukey HSD test, $p<0.01$ in 2010; $p=0.027$ in 2011; $p<0.01$ in 2012). Symbiodinium densities ranged from $1.27 \sim 2.79 \times 10^{4}$ cells planula ${ }^{-1}$ at $27^{\circ} \mathrm{C}$, while they ranged from $0.0004 \sim 0.33 \times 10^{4}$ cells planula ${ }^{-1}$ at $32{ }^{\circ} \mathrm{C}$. The Symbiodinium cell density at medium temperature $\left(31{ }^{\circ} \mathrm{C}\right.$ in 2010 and $30^{\circ} \mathrm{C}$ in 2012) was not significantly different from the control (Fig. 2) (Tukey HSD test, $p=0.57$ and $p=0.105$ in 2010 and 2012, respectively). The final

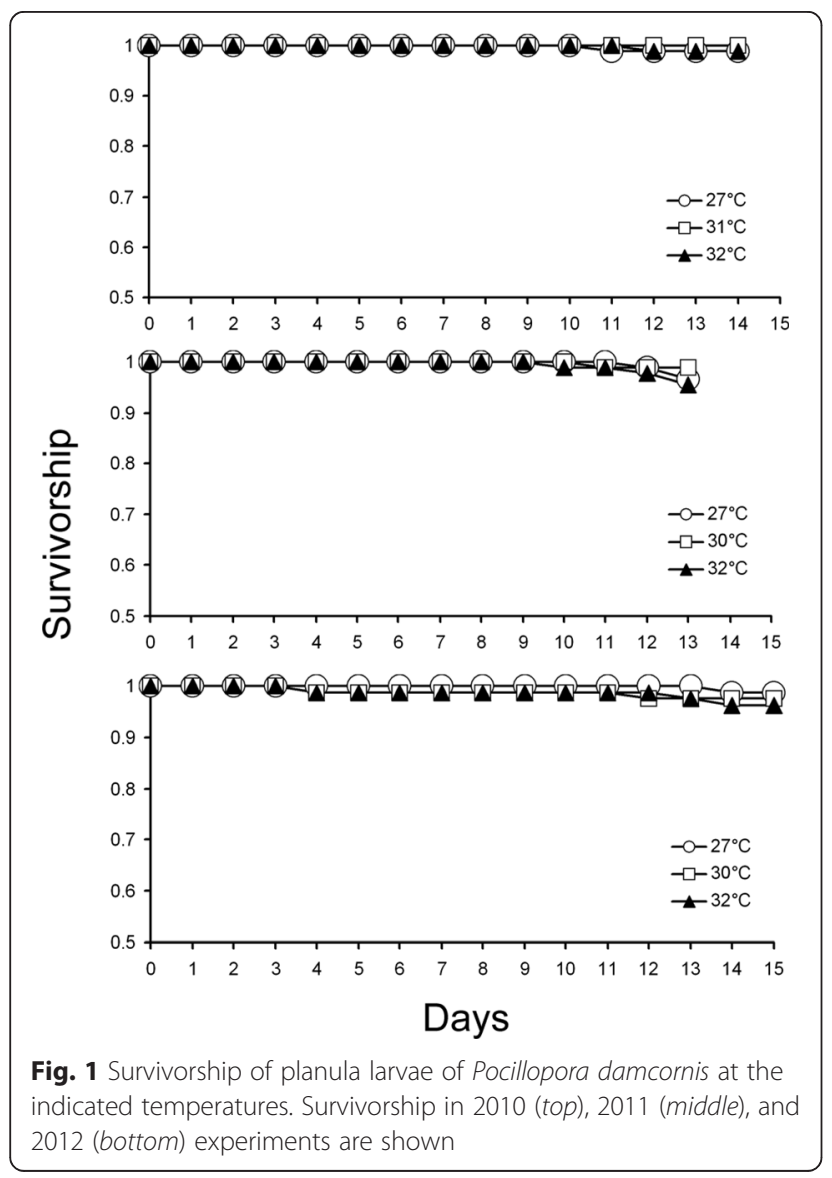

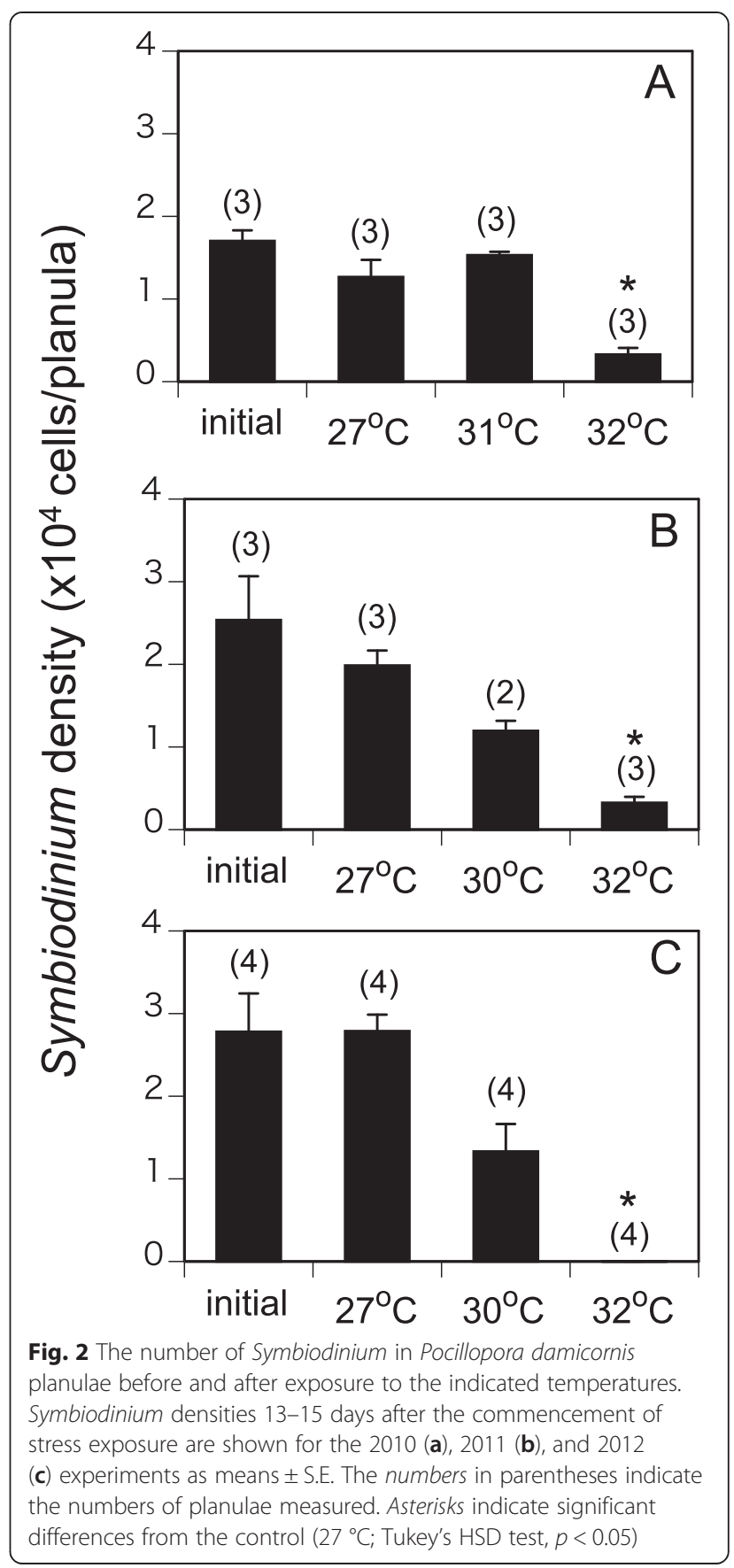

symbiont density at the medium temperature $\left(30{ }^{\circ} \mathrm{C}\right)$ in the 2011 experiment was not included in the statistical analysis because the number of replicates was fewer than three.

\section{Symbiodinium genotypes of maternal Pocillopora damicornis colonies}

Symbiodinium type was analyzed in three colonies that were used as source of planulae in the 2011 experiment. 
Multiple types of Symbiodinium were found to be associated with $P$. damicornis colonies, including subclade A1, C1, C3 and C71 in colony $1, \mathrm{~A} 1$ in colony 2, and $\mathrm{A} 1, \mathrm{C} 1$, and $\mathrm{C} 3$ in colony 3 .

\section{Apoptotic cells in Pocillopora damicornis larvae exposed to thermal stress}

The TUNEL assay of longitudinal sections of $P$. damicornis larvae exposed to $31{ }^{\circ} \mathrm{C}$ for 2 weeks showed a high number of TUNEL-positive (apoptotic) cells, especially in the gastrodermis (Fig. 3). The proportion of apoptotic cells was significantly higher in the gastrodermis than in the epidermis in 27 and $31{ }^{\circ} \mathrm{C}$ treatment groups (Fig. 4, Welch's $t$-test, $\mathrm{df}=2.006, p<0.05 ; \mathrm{df}=2.259, p<0.05$ ), while no difference was detected in the $32{ }^{\circ} \mathrm{C}$-treated groups (Welch's $t$-test, $\mathrm{df}=2.497, p=0.2032$ ). Only $4.5 \pm$ $2.9 \%$ of apoptotic cells were in the epidermis at $27{ }^{\circ} \mathrm{C}$, with twice that amount at $12.2 \pm 0.1 \%$ in the

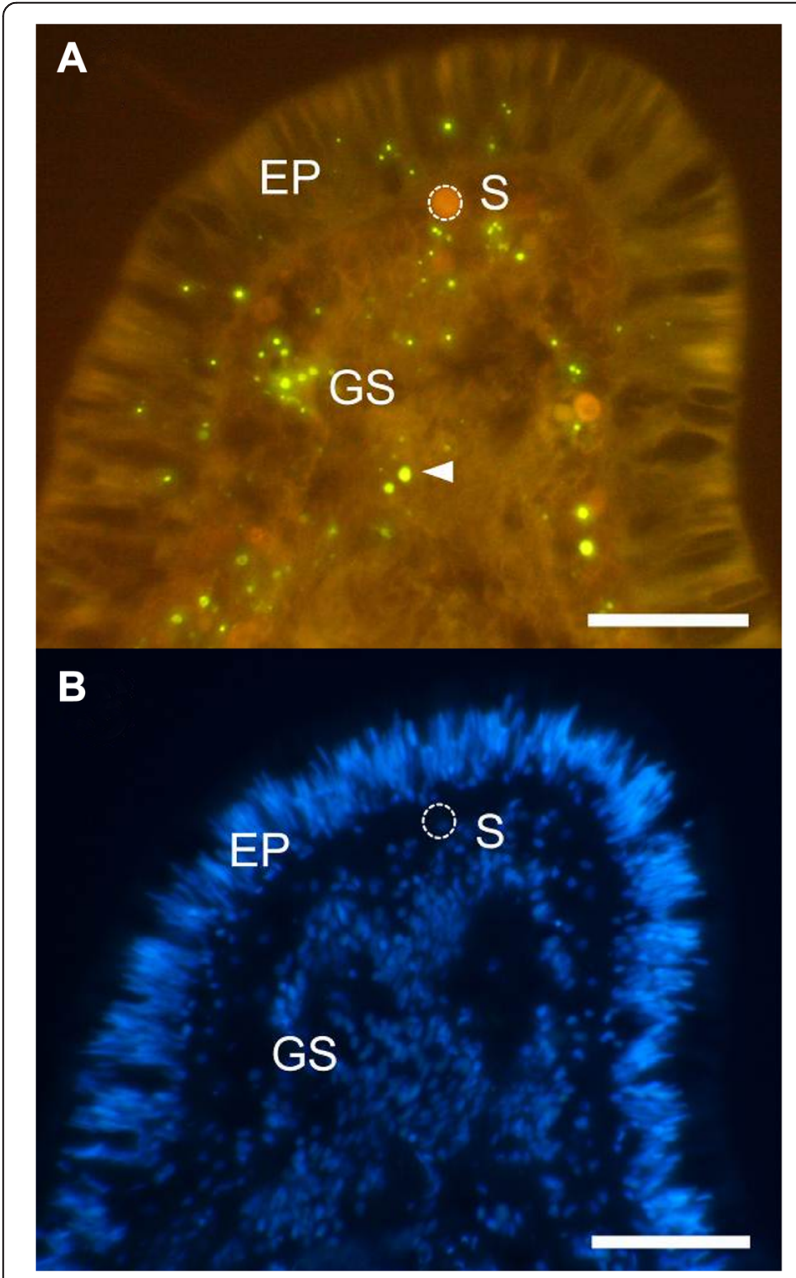

Fig. 3 Photomicrographs of longitudinal sections of a Pocillopora damicornis planula. a TUNEL assay. b DAPI-stained nuclei. EP, epidermis; GS, gastrodermis; S, Symbiodinium cells; arrowhead, TUNEL-positive signal. Scale bar, $50 \mu \mathrm{m}$

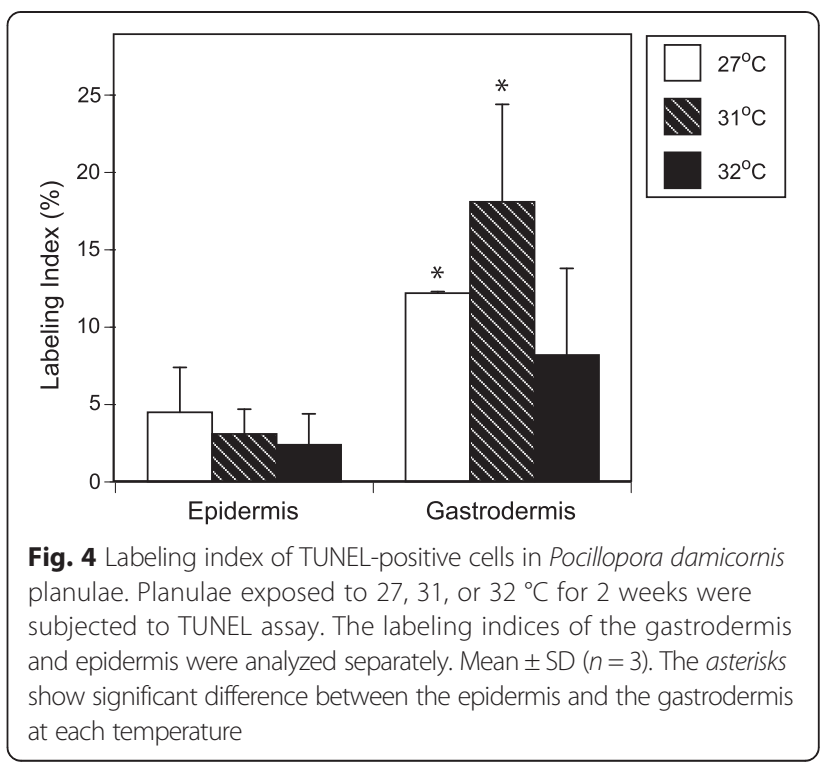

gastodermis. Furthermore, only $3.1 \pm 1.6 \%$ apoptotic cells were in the epidermis at $31{ }^{\circ} \mathrm{C}$, while the highest numbers recorded $(18.1 \pm 6.3 \%)$ were in the gastrodermis. However, differences among the number of apopotoic cells in the gastrodermis of larvae exposed to different temperatures were not significant (one-way ANOVA, $\mathrm{df}=$ $2, p=0.1173$ ). Many apoptotic signals were observed in the gastrodermis of $31{ }^{\circ} \mathrm{C}$-treated planulae, while diffuse TUNEL-positive signals were occasionally observed in the epidermis of $32{ }^{\circ} \mathrm{C}$-treated planulae. Diffuse TUNELpositive signals that extended more than a third of epidermis thickness were observed only in one out of three planulae exposed to $32{ }^{\circ} \mathrm{C}$. The number of such diffuse signals was low (1-3 per section of the whole planula) and was not included in the labeling index, as counting the number of TUNEL-positive nuclei was difficult in such cases.

\section{Discussion}

Previous studies on Acropora larvae inoculated with Symbiodinium isolated from adult colonies have shown that symbiotic larvae are more sensitive to thermal or strong light stress than are Symbiodinium-free larvae (Yakovleva et al. 2009; Nesa et al. 2012). Larvae containing Symbiodinium show lower survivorship, higher levels of antioxidant enzyme activity and lipid peroxidation, and more severe DNA damage under thermal or strong light stress (Yakovleva et al. 2009; Nesa et al. 2012). However, few studies have investigated the survivorship or stress susceptibility of symbiotic larvae of vertical transmitter corals (Cumbo et al. 2013). We postulated that the symbiotic larvae of $P$. damicornis would be more stress sensitive than the Symbiodinium-free larvae of horizontal transmitter corals. Contrary to our expectations, $P$. damicornis planulae with high numbers of 
symbionts $\left(2-3 \times 10^{4}\right.$ cells/planula) exhibited high survivorship at a high temperature $\left(32{ }^{\circ} \mathrm{C}\right)$ under medium light intensity $\left(100 \mu \mathrm{mol} \mathrm{m}{ }^{-2} \mathrm{~s}^{-1}\right)$. There was no significant difference in survivorship among larvae exposed to 27,30 or 31 , and $32{ }^{\circ} \mathrm{C}$ for at least $13-15$ days. Symbiotic planulae of $P$. damicornis showed higher survivorship than Symbiodinium-free larvae of Acropora corals as well as larvae inoculated with homologous symbionts at high temperatures. For example, Baird et al. (2006) reported that the survivorship of both symbiotic and non-symbiotic larvae of $A$. muricata decreased to $\sim 30 \%$ after a 7 -day exposure to 28 or $32{ }^{\circ} \mathrm{C}$. Yakovleva et al. (2009) reported that the survivorship of A. intermedia larvae inoculated with Symbiodinium from their parents decreased to $50 \%$ after 4 days of exposure to $32{ }^{\circ} \mathrm{C}$.

Despite having high survivorship, the Symbiodinium cell density of $P$. damicornis larvae significantly decreased at $32{ }^{\circ} \mathrm{C}$. $P$. damicornis larvae may potentially have the capacity to reduce their symbiont numbers under thermal stress, thereby reducing the oxidative stress within their tissue. This could lead to higher survival rates of larvae under stressful conditions, like what is seen in our study. This agrees with recent research that showed that adult corals with high symbiont-to-host cell ratios were more susceptible to bleaching (Cunning and Baker 2013). Therefore, lower Symbiodinium cell densities are advantageous to corals under thermal stress.

While larvae exposed to $31{ }^{\circ} \mathrm{C}$ retained most of the symbionts in the 2010 experiment, high percentages of apoptotic cells were observed in the gastrodermis of the larvae. The percentage of apoptotic cells in the gastrodermis was significantly higher than that in the epidermis. When adult branches of the coral Acropora aspera were exposed to thermal stress, apoptosis of gastrodermal cells was initially observed before the onset of bleaching (Ainsworth et al. 2008). These observations suggest that ROS generated by symbiotic algae induce apoptosis in host gastrodermal cells at early stages of stress response. The frequency of apoptotic cells in the gastrodermis appeared to be lower in the $32{ }^{\circ} \mathrm{C}$-treated, bleached larvae than in the $31^{\circ} \mathrm{C}$-treated, pre-bleaching larvae, although the difference was not significant. This is also consistent with the idea that $P$. damicornis larvae tolerate the thermal stress via reduction of their symbiont densities. It is, however, not clear why the gastrodermis exhibited higher proportion of apoptotic cells than the epidermis even in the control larvae kept at $27^{\circ} \mathrm{C}$ in the present study.

In addition to the hypothesis described above, there are several other possible mechanisms by which $P$. damicornis larvae acquire high thermal tolerance. Tchernov et al. (2011) suggested that if the caspase cascade, a process that is activated by apoptotic stimulation and leads to apoptotic cell death was arrested at an early stage, the apoptotic response would not occur and the host would survive the thermal stress, even though it suffered bleaching. It is possible that $P$. damicornis larvae possess a mechanism to suppress the apoptotic pathway to a relatively low level under thermal stress. If so, this may enhance survival of $P$. damicornis larvae under thermal stress. This possibility warrants further investigation. Recently, Padilla-Gamiño et al. (2013) reported that eggs of Montipora capitata, a vertical transmitter coral, contain higher concentrations of manganese super oxide dismutase (MnSOD) and higher levels of ubiquitin conjugate than adult colonies. M. capitata is a spawner, and its larvae has the potential to stay at the ocean surface, where light levels are high, for long periods of time. The high concentrations of antioxidants in the eggs likely pass into the larvae thereby increasing larval survival under light stress at the ocean surface. Although it is not clear how long $P$. damicornis larvae stay at the ocean surface, it is likely that $P$. damicornis larvae also have a more efficient antioxidant system than adult colonies. This should be confirmed in future studies.

It is also possible that the symbionts associated with $P$. damicornis larvae are highly stress resistant. In this study, Symbiodinium type A1 was present in all three maternal colonies, while $\mathrm{C} 1, \mathrm{C} 3$, and $\mathrm{C} 71$ were found to be associated with only some of the colonies. A previous study also showed that $P$. damicornis colonies from Okinawa are associated with multiple Symbiodinium types A1 and C1 (Magalon et al. 2007). McGinty et al. (2012) reported that type A1 was tolerant and exhibited no increase in ROS production at high temperature $\left(31{ }^{\circ} \mathrm{C}\right)$. If $\mathrm{A} 1$ is the dominant symbiont in the larvae used in this study, this might account for the high stress tolerance of $P$. damicornis larvae. It remains to be determined whether the dominant symbiont in the larvae was A1, though it is likely that larvae contained a symbiont composition similar to that of their maternal colonies.

\section{Conclusions}

Generally, symbiotic larvae are expected to be more susceptible to environmental stress than non-symbiotic larvae as symbiotic algae become a source of reactive oxygen species under stressful conditions. However, $P$. damicornis larvae, despite having large numbers of Symbiodinium, exhibited high tolerance to thermal stress. While symbiont numbers were significantly reduced in larvae under high temperatures, larval survival remained high. This shows that $P$. damicornis larvae have the capacity to reduce the symbiont cell density without a harmful effect on their survivorship under thermal stress. Further studies on antioxidant systems, association with tolerant symbiont types, and possible 
suppression of apoptotic pathways might provide insight into the high stress tolerance of symbiotic larvae of P. damicornis.

\section{Competing interests}

The authors declare that they have no competing interests.

\section{Authors' contributions}

$\mathrm{DH}$ and $\mathrm{MH}$ conceived and designed the experiments. $\mathrm{DH}$ carried out the survival experiments. NY carried out TUNEL assay and apoptosis data analysis. SH carried out the Symbiodinium identification. $\mathrm{DH}$ and $\mathrm{MH}$ drafted the manuscript, while NY and SH also wrote their parts of the manuscript. All authors read and approved the final manuscript.

\section{Acknowledgements}

We would like to thank Sesoko Station, Tropical Biosphere Research Center, University of the Ryukyus, where part of this study was conducted. This study was supported in part by the International Research Hub Project for Climate Change and Coral Reef/sland Dynamics of University of the Ryukyus and a Grant-in-Aid for Scientific Research in Innovative Areas, Coral Reef Science, from the Ministry of Education, Culture, Sports, Science and Technology, Japan.

\section{Author details}

'Department of Chemistry, Biology and Marine Science, University of the Ryukyus, Nishihara, Okinawa 903-0213, Japan. ${ }^{2}$ Sesoko Station, Tropical Biosphere Research Center, University of the Ryukyus, Motobu, Okinawa 905-0227, Japan.

Received: 11 July 2014 Accepted: 16 July 2015

Published online: 24 July 2015

\section{References}

Abrego D, Ulstrup KE, Willis BL, van Oppen MJH (2008) Species-specific interactions between algal endosymbionts and coral hosts define their bleaching response to heat and light stress. Proc R Soc Biol Sci Ser B 275:2273-2282

Ainsworth TD, Hoegh-Guldberg O, Heron SF, Skirving WJ, Leggat W (2008) Early cellular changes are indicators of pre-bleaching thermal stress in the coral host. J Exp Mar Biol Ecol 364:63-71

Baird AH, Gilmour JP, Kamiki TM, Nonaka M, Pratchett MS, Yamamoto HH, Yamasaki H (2006) Temperature tolerance of symbiotic and non-symbiotic coral larvae. In: Proc 10th Int Coral Reef Symp 1., pp 38-42

Baird AH, Guest JR, Willis BL (2009a) Systematic and biogerographical patterns in the reproductive biology of scleractinian corals. Annu Rev Ecol Evol Syst 40:551-571

Baird AH, Bhagooli R, Ralph PJ, Takahashi S (2009b) Coral bleaching: the role of the host. Trends Ecol Evol 24:16-20

Baker AC, Starger CJ, McClanahan TR, Glynn PW (2004) Coral reefs: coral's adaptive response to climate change. Nature 430:741-741

Berkelmans R, van Oppen MJH (2006) The role of zooxanthellae in the thermal tolerance of corals: a 'nugget of hope' for coral reefs in an era of climate change. Proc R Soc Biol Sci Ser B 273:2305-2312

Cantin NE, van Oppen MJH, Willis BL, Mieog JC, Negri AP (2009) Juvenile corals can acquire more carbon from high-performance algal symbionts. Coral Reefs 28:405-414

Cumbo VR, Fan TY, Edmunds PJ (2013) Effects of exposure duration on the response of Pocillopora damicornis larvae to elevated temperature and high $\mathrm{pCO}_{2}$. J Exp Mar Biol Ecol 439:100-107

Cunning R, Baker AC (2013) Excess algal symbionts increase the susceptibility of reef corals to bleaching. Nat Climate Change 3:259-262

Cunning R, Gillette P, Capo T, Galvez K, Baker AC (2015) Growth tradeoffs associated with thermotolerant symbionts in the coral Pocillopora damicornis are lost in warmer oceans. Coral Reefs 34:155-160

Franklin EC, Stat M, Pochon X, Putnam HM, Gates RD (2012) GeoSymbio: a hybrid, cloud-based web application of global geospatial bioinformatics and ecoinformatics for Symbiodinium-host symbioses. Mol Ecol Res 12:369-373

Glynn PW, Maté JL, Baker AC, Calderon MO (2001) Coral bleaching and mortality in Panama and Ecuador during the 1997-1998 El Niño-Southern Oscillation event: spatial/temporal patterns and comparisons with the 1982-1983 event. Bull Mar Sci 69:79-109
Harii S, Kayanne H, Takigawa H, Hayashibara T, Yamamoto M (2002) Larval survivorship, competency periods and settlement of two brooding corals, Heliopora coerulea and Pocillopora damicornis. Mar Biol 141:39-46

Harii S, Yamamoto M, Hoegh-Guldberg O (2010) The relative contribution of dinoflagellate photosynthesis and stored lipids to the survivorship of symbiotic larvae of the reef-building corals. Mar Biol 157:1215-1224

Harrison PL (2011) Sexual reproduction in scleractinian corals. In: Dubinsky Z, Stambler N (eds) Coral reefs: an ecosystem in transition. Springer, Netherlands, pp 59-85

Harrison PL, Wallace CC (1990) Reproduction, dispersal and recruitment of scleractinian corals. In: Dubinsky Z (ed) Coral reefs, ecosystems of the world 25. Elsevier, Amsterdam, pp 133-207

Hidaka M, Yurugi K, Sunagawa S, Kinzie RA III (1997) Contact reactions between young colonies of the coral Pocillopora damicornis. Coral Reefs 16:13-20

Hoegh-Guldberg O, Mumby PJ, Hooten AJ, Steneck RS, Greenfield P, Gomez E, Harvell CD, Sale PF, Edwards AJ, Caldeira K, Knowlton N, Eakin CM, IglesiasPrieto R, Muthiga N, Bradbury RH, Dubi A, Hatziolos ME (2007) Coral reefs under rapid climate change and ocean acidification. Science 318:1737-1742

LaJeunesse TC, Loh WKW, van Woesik R, Hoegh-Guldberg O, Schmidt GW, Fitt WK (2003) Low symbiont diversity in southern Great Barrier Reef corals, relative to those of the Caribbean. Limnol Oceanogr 48:2046-2054

Magalon H, Flot JF, Baudry E (2007) Molecular identification of symbiotic dinofagellates in Pacifc corals in the genus Pocillopora. Coral Reefs 26:551-558

McGinty ES, Pieczonka J, Mydlarz LD (2012) Variations in reactive oxygen release and antioxidant activity in multiple Symbiodinium types in response to elevated temperature. Microb Ecol 64:1000-1007

Nesa B, Hidaka M (2008) Thermal stress increases oxidative DNA damage in coral cell aggregates, Proc $11^{\text {th }}$ Int Coral Reef Symp (Florida)., pp 144-148

Nesa B, Hidaka M (2009) High zooxanthellae density shortens the survival time of coral cell aggregates under thermal stress. J Exp Mar Biol Ecol 368:81-87

Nesa B, Baird AH, Harii S, Yakovleva I, Hidaka M (2012) Algal symbionts increase DNA damage in coral planulae exposed to sunlight. Zool Stud 51:12-17

Padilla-Gamiño JL, Pochon X, Bird C, Concepcion GT, Gates RD (2012) From parent to gamete: vertical transmission of Symbiodinium (Dinophyceae) ITS2 sequence assemblages in the reef building coral Montipora capitata. PLoS One 7, e38440

Padilla-Gamiño JL, Bidigare RR, Barshis DJ, Alamaru A, Hédouin L, HernándezPech X, Kandel F, Soon SL, Roth MS, Rodrigues LJ, Grottoli AG, Portocarrero C, Wagenhauser SA, Buttler F, Gates RD (2013) Are all eggs created equal? A case study from the Hawaiian reef-building coral Montipora capitata. Coral reefs 32:137-152

Saragosti E, Tchernov D, Katsir A, Shaked Y (2010) Extracellular production and degradation of superoxide in the coral Stylophora pistillata and cultured Symbiodinium. PLoS One 5, e12508

Sinniger F, Reimer JD, Pawlowski J (2010) The Parazoanthidae (Hexacorallia: Zoantharia) DNA taxonomy: description of two new genera. Mar Biodiv 40:57-70

Tchernov D, Kvitt H, Haramaty L, Bibby TS, Gorbunov MY, Rosenfeld H, Falkowsky PG (2011) Apoptosis and the selective survival of host animals following thermal bleaching in zooxanthellate corals. Proc Natl Acad Sci U S A 108:9905-9909

van Oppen MJH, Mahiny AJ, Done TD (2005) Geographic distribution of zooxanthella types in three coral species on the Great Barrier Reef sampled after the 2002 bleaching event. Coral Reefs 24:482-487

Weis VM (2008) Cellular mechanisms of Cnidarian bleaching: stress causes the collapse of symbiosis. J Exp Biol 211:3059-3066

Yakovleva IM, Baird AH, Yamamoto HH, Bhagooli R, Nonaka M, Hidaka M (2009) Algal symbionts increase oxidative damage and death in coral larvae at high temperatures. Mar Ecol Prog Ser 378:105-112 